\title{
Um ponto cego de OMal-estar na Cultura: a Ciência na era da Instalação
}

\author{
NELSON DA SILVA JUNIOR ${ }^{I}$
}

$\mathrm{F}$ REUD, em sua conhecida conferência Sobre uma visão de mundo, afirma que Psicanálise é indissociável de uma visão de mundo em sua forma empírico-positivista, isto é, de uma Weltanschauung científica (Freud, 1982d). Trata-se de uma visão de ciência pautada pela busca paciente e fragmentária do saber, distante, portanto, de uma visão de mundo totalizante como seria o caso da Weltanschaunng religiosa, por exemplo. Ora, tal visão é responsável, segundo penso, pela impossibilidade de Freud responder conceitualmente à mudança do lugar social da racionalidade científica a partir do início do século XX. Com efeito, Freud considera a ciência com uma forma de saber imune às aspirações infantis de proteção, orientação e amor presentes nas instituições religiosas e nas propostas políticas utópicas como o marxismo. Contudo, tal expectativa não foi confirmada pelos fatos, que demonstram que, tal como a religião ou as grandes narrativas políticas, também a linguagem científica poderia funcionar como um discurso moral que reencena e satisfaz as expectativas infantis em cada um de nós. Essa mudança do lugar social da ciência foi articulada a processos sociais homólogos, principalmente a recentralização da cultura em torno da economia.

A homologia em questão é assumida a partir da interpretação heideggeriana da cultura, que aponta para uma alteração radical na linguagem e na relação do homem com o mundo, ao mesmo tempo que para uma inversão entre o que se entende como sendo as relações entre ciência e técnica em $A$ questão da técnica (Heidegger, 1990). Enquanto exemplo da precipitação concreta dessa mudança do lugar da ciência na cultura será retomada aqui a mudança dos discursos acadêmico-empresariais sobre o sofrimento e na forma de expressão individual pela qual esses discursos institucionais se concretizam. Assim, será preciso examinar primeiramente o modo como uma nova Psiquiatria se estabeleceu na segunda metade do século XX a partir de duas mudanças radicais em seu funcionamento. Em primeiro lugar, pela inversão de lugares entre a teoria e a técnica em sua clínica, e, em segundo lugar, pela sua "elevação" a uma lógica industrial, indissociável da manipulação dos consumidores pelo marketing. Por um lado, a própria diagnóstica do sofrimento psíquico, isto é, a compreensão da natureza do conhecimento científico sobre o adoecimento da alma se viu alterada. Por outro, tais mudanças do lugar da ciência e da linguagem natural 
possuem efeitos sobre os modos de narração do sofrimento, como a rarefação da figura do destino nas narrativas autobiográficas do sujeito (Silva Jr., 2008). Farei aqui uso do conceito foucaultiano de modos de subjetivação para a compreensão dessas novas formas de expressão, o que nos permitirá isolar a espessura social dessa mudança na linguagem no âmbido da narração que o sujeito faz de seu sofrimento. A descrição das mudanças na diagnóstica e na narração do sofrimento é uma condição para que possamos examinar a impossibilidade, para a teoria freudiana, de diagnosticar essa mudança do lugar social da ciência e seus efeitos na economia psíquica do sujeito.

Esse caminho, que permite igualmente localizar esse "ponto cego" na teoria freudiana, traz consigo a necessidade de um amplo reposicionamento conceitual da Psicanálise diante da cultura. Tal como demostra Askofaré (2013, p.54), um dos principais pivôs que marcam a diferença entre Lacan e Freud diz respeito, precisamente, ao posicionamento de cada um deles frente à ciência. Com efeito, conforme o autor, Lacan via na ciência não um saber, mas uma prática da verdade análoga, ou equivalente, à da Psicanálise. Sem dúvida, a teoria dos discursos de Lacan, particularmente aquela do discurso da ciência e do discurso do capitalista, representa um passo inquestionável nesse reposicionamento (Askofaré, 2013). Contudo, na medida em que tais conceitos não foram apresentados como uma solução às deficiências conceituais da teoria freudina, cabe retomar, ainda que em linhas gerais, uma justificativa epistemológica das futuras proposições lacanianas. Comecemos, portanto, pela retomada das balizas mestras da teoria freudiana do Mal-estar da cultura.

\section{O mal-estar da cultura segundo Freud entre a antropologia filosófica e a filosofia da história}

Do ponto de vista histórico, a ideia de uma oposição estrutural entre a vida pulsional e a cultura como origem do sofrimento aparece relativamente cedo em Freud (1986): no Manuscrito N, na carta para Fliess de 31 de maio de 1897, seu comentário sobre o incesto é que "ele é $[\ldots]$ antissocial - a cultura consiste nesta renúncia contínua". Dois anos depois, surge, definitivamente, a tese que a cultura seja uma das causas das patologias psíquicas. No texto $A$ sexualidade na etiologia das neuroses, a relação causal é explícita. Freud ali afirma que podemos "com correção responsabilizar também nossa civilização pela disseminação da neurastenia" (Freud, 1982a, p. 29).

Não se trata, portanto, para Freud, de meramente apontar as "relações antagônicas entre cultura e livre desenvolvimento da sexualidade" (Freud, 1905, Bd. 5, 144), mas também de compreender os efeitos patológicos decorrentes desse antagonismo. Assim, desde o início, tal antagonismo parece se dar em uma estrutura de impasse entre a natureza e a cultura: por um lado, o recalcamento pulsional é necessário para a instauração da cultura; por outro, seus efeitos serão patológicos sobre os sujeitos e suas relações “culturalizadas". Há, assim, uma relação de determinação dificilmente contornável entre as condições de possi- 
bilidade de instauração da cultura e seus efeitos patológicos sobre essa mesma cultura. Ao longo de sua obra, os efeitos patológicos em questão, ou seja, as patologias do social, sofrem no pensamento freudiano uma alteração de modalidade e de conteúdo (Silva Jr., 2012a). Quanto à modalidade, elas passam de um estatuto de contingência para um estatuto de necessidade. Em outras palavras, num primeiro momento, Freud concebe uma conciliação possível entre pulsionalidade e cultura sem resto patológico. Mas a partir de 1920, tal conciliação se torna conceitualmente impossível. Quanto à alteração de conteúdo nessa estrutura de impasse entre pulsionalidade, cultura e patologia, essa será definida pelo advento da pulsão de morte e sua "crueldade sem álibi", expressão com a qual Jacques Derrida (2000) aponta para o caráter sem razão, sem outra finalidade dessa crueldade senão a própria crueldade e sua volúpia de destruição (Silva Jr., 2012b). Vejamos como isso se dá.

Num primeiro momento, Freud assume que qualquer organização social requer uma renúncia à satisfação pulsional. Ora, tal renúncia é compensada seja por formas deformadas de satisfação, a saber, os sintomas neuróticos, seja pela sublimação, isto é, por expressões culturalmente aceitáveis da sexualidade. Se esse esquema parecia funcionar bem até 1920, a partir dessa data, a nova teoria pulsional de Freud impede a solução sublimatória com um novo argumento. Segundo Freud, toda sublimação exigiria uma regressão libidinal preliminar ao seu posterior desvio para novos objetos socialmente valorizados. Esse retorno ao narcisismo teria como efeito uma deserotização importante da libido. Essa deserotização, por sua vez, teria como efeito a desfusão das pulsões eróticas e da pulsão de morte, liberando esta última para refusões particularmente nefastas, como aquela presente na origem do masoquismo moral, e feminino. De fato, nessa versão final da etiologia cultural do sofrimento, uma implacável lógica é proposta pelo pensamento freudiano: o mal-estar da civilização adquire uma segunda faceta, ao lado daquela dos sintomas neuróticos, a saber, aquela da deserotização e da consequente liberação de forças pulsionais agressivas, forças que o psiquismo buscaria dominar através de soluções masoquistas, expressas fundamentalmente pelo sentimento de culpa inconsciente (Silva Jr., 2014).

Nesse nível de teorização, o que está sendo colocado em jogo por Freud é evidentemente da ordem de uma antropologia filosófica preocupada em compreender a diferença entre a animalidade e o humano, assim como a passagem que leva de uma à outra. Tal antropologia filosófica pensa o humano não apenas como um ser dividido entre a natureza e a cultura, mas também como um ser que sofre de forma inevitável o preço dessa divisão. Tanto o corpo quanto a alma do homem culturalizado trarão a marca da dor de modo perene. Claro está que se a concepção freudiana das patologias do social se resumisse a esse eixo antropológico, ela dificilmente poderia escapar à crítica de um impasse frente à ordem política, onde a pressuposição de uma margem de liberdade frente às ações futuras é uma condição de possibilidade. 
Contudo, esse é apenas um dos dois centros causais da teoria das patologias do social em Freud, uma vez que sua obra avança outro elemento causal de origem social para o sofrimento psíquico. A figura da elipse (Hamacher, 1999), pode ilustrar esse modelo bicêntrico das patologias do social, pois tem dois centros na origem de sua construção. Se o primeiro centro da elipse causal freudiana é aquele de uma antropologia filosófica, o segundo centro se inscreve numa filosofia da história. Nesse segundo centro, Freud atribui uma indeclinável eficácia patogênica ao problema da verdade. Mais especificamente, à relação deficitária dos discursos com a verdade histórica dos sujeitos e de sua vida pulsional. Assim, concepções sobre a origem e manutenção das instituições, identidades e tradições culturais, valores e costumes, enfim tudo aquilo que se define na filosofia contemporânea sob a ordem dos discursos, podem exercer o papel de novos fatores que se articulam ao fator etiológico primeiro das patologias do social, postulado por sua antropologia filosófica, potencializando-o. Em outras palavras, as grandes narrativas de uma cultura, seus ideais, suas exigências morais, podem fazer adoecer na medida em que estabeleçam relações deficitárias dos seus sujeitos com a verdade de sua história e de seus desejos.

Para Freud, a partir do centro discursivo da elipse causal, é possível modificar, dentro de certos limites, os efeitos patogênicos do centro antropológico. De fato, a relação dos sujeitos com a verdade pode potencializar ou atenuar o sofrimento proveniente da estrutura de impasse entre a natureza e a cultura. Eis onde se localiza, para Freud, o papel propriamente político das teses psicanalíticas. Com efeito, desde 1908, em A moral sexual civilizada e a neurose moderna, Freud convida a sociedade burguesa a uma autorreflexão a respeito de suas normas e valores, sugerindo explicitamente a franqueza e a verdade a respeito dos assuntos sexuais como os melhores remédios para a hipocrisia moral da época e suas consequências de caráter epidêmico, a saber, a histeria nas mulheres, a impotência sexual nos homens. Em 1930, em O mal-estar na civilização, a acusação de hipocrisia moral se volta contra os discursos que negam a natureza incontornavelmente agressiva do ser humano. Claro está que, se por um lado, a Psicanálise aponta para o caráter inevitável do mal-estar da vida em civilização, ela também aposta na minimização de tal sofrimento, buscando reduzir a dor neurótica ao sofrimento humano comum, através do reconbecimento de verdades incompatíveis com nossos ideais e com nossas aspirações infantis de proteção e orientação moral.

Assim, as teses freudianas sobre o sofrimento inerente e inevitável da vida em sociedade não impedem a realização de uma crítica social genuinamente psicanalítica, que preserva o sentido crítico das formas de sofrimento e sua potência de transformação. Em Por que a Guerra? Freud (1982c) nomeia esse tipo de ação sobre o campo pulsional mediada pela palavra como uma terapêutica indireta. Os discursos sociais, seja na forma da religião, seja na da ideologia política, propõem, segundo Freud, valores essencialmente inadequados, e invariavelmen- 
te ilusórios, à natureza pulsional humana. Nesse sentido, o impasse político da antropologia filosófica freudiana se abre, e permite uma reflexão crítica de longo alcance com relação aos efeitos deletérios, para a vida humana, das utopias políticas e de outras visões totalizantes de mundo. Inversamente, o confronto com a verdade pode atenuar o fator etiológico oriundo da hominização e introduzir o pensamento político a uma lógica simultaneamente crítica e cautelosa: por um lado, uma política inspirada pela suspeita frente ao entusiasmo das soluções utópicas; por outro, uma política inspirada pela experiência clínica, onde o cuidado tem a primazia sobre conhecimento causal da doença e o projeto de sua cura definitiva.

Entende-se desse modo por quê, independentemente das mudanças de modalidade e de conteúdo operadas em sua antropologia filosófica - fundamentalmente a introdução de uma nova economia pulsional e seus correlatos como a pulsão de morte -, as críticas de Freud, quando se trata de encontrar na cultura o fator agravante das patologias, se dirigem invariavelmente a um mesmo alvo ao longo do tempo, a saber, a relação deficitária dos discursos com a verdade. Das duas origens de nosso sofrimento, apenas nossa relação com a verdade pode ser eventualmente modificada. Os alvos constantes, considerados por Freud como fontes nefastas e da inverdade, são a moralidade burguesa, fundamentalmente hipócrita com relação à sexualidade, e as religiões, particularmente a cristã, fundada sobre o preceito paulino do "amai ao próximo como a ti mesmo". Nessa cruzada freudiana pela verdade, a baliza inquestionável do pensamento só poderia ser oferecida pela ciência, ou seja, da abordagem racional, e até certo ponto cética, diante dos limites de nosso saber frente aos perigos do mundo. Apenas a Weltanschauung, a visão de mundo científica, teria, para Freud, condições de representar uma referência confiável frente à insaciável sede de autoilusão do homem.

De fato, uma visão de mundo é definida por Freud como "uma construção intelectual que resolve de modo homogêneo todos os problemas de nossa existência a partir de uma hipótese que organiza o todo, e onde, consequentemente, nenhum problema permanece em aberto, e onde tudo pelo que nos interessamos encontra seu lugar determinado" (Freud, 1982d, p.586). As religiões, a filosofia e alguns movimentos políticos se fundariam, para Freud, nessa forma totalizante de narrativas. Já a visão de mundo da ciência, contudo, teria uma diferença importante em relação a isso: a homogeneidade por ela buscada em suas explicações seria apenas uma direção, um programa cujo momento de realização não seria previsível. Desse modo, em vez da totalidade e da imediatez, a Weltanschauung científica seria definida pela fragmentariedade, pela incompletude e pelo adiamento de sua relação com a verdade. Nesse progresso assimptótico, a ciência se fundaria em observações minuciosas, no incansável trabalho intelectual e em uma constante recusa do conhecimento por revelações, intuições ou arte divinatória. 
Cabe agora demonstrar de que modo a suposição de uma relação indissociável da ciência com a verdade se apresenta como estruturalmente inadequada diante de uma mudança radical do lugar da ciência na cultura.

\section{A ciência e a linguagem na era da Instalação: Die Gestell}

Já nos anos 1930, Heidegger começava a perceber os problemas com a via na qual trilhava Ser e tempo, publicado no final da década anterior (Heidegger, 1979). Por exemplo, a afirmação de uma autonomia radical, vivida individualmente pelo Dasein, não lhe parecia mais efetivamente ter efeitos sobre uma nova forma de alienação que começava a surgir em uma série de fenômenos sociais.

De fato, logo após a publicação do que era pensada como apenas a primeira parte do Ser e tempo, Ernst Jünger publicara A mobilização total (Jünger, 1960), livro que descrevia uma peculiar forma de organização social que a Primeira Guerra Mundial havia trazido à luz. Jünger sublinhava ali uma ruptura na lógica dessa guerra com relação a todas as outras da história. Até então, observa ele, as guerras eram um problema exclusivamente militar, e restrito aos Estados e às forças armadas. Contudo, na Guerra de 1914, Jünger observa que todas as instituições sociais, todo o povo dos países envolvidos se viram convocados a participar da guerra, donde o título de seu texto A mobilização total. Para além dos "negócios de guerra" revelava-se ali uma nova forma de organização da vida social e da cultura.

Para Heidegger, isso apontou para uma questão que transcendia o seu projeto inicial de desconstrução da metafísica, basicamente esse fenômeno apontado por Jünger mostrava que o problema ultrapassava seu âmbito propriamente filosófico. Além disso, o fato demonstrava que, naquele momento histórico, a essência da experiência de alienação e de sua eventual superação não poderia mais ser pensada como exclusivamente individual como o fora em Ser e tempo. Não apenas a vida do indivíduo parecia orientada pela alienação metafísica, mas as formas de vida como tais, as instituições e a linguagem haviam tomado a forma de um sistema metafísico, isto é, a forma de uma afirmação totalitária e totalizante do Ente como presença. Em outras palavras, a recusa de pensar seus próprios fundamente feita pela metafísica, recusa que Heidegger diagnosticara como recusa da finitude em Ser e tempo, se expressava também indubitavelmente na própria vida social, para além da reflexão filosófica. Desse modo, não apenas a alienação metafísica do Ser deixa de ser pensável como uma questão individual de fuga, de angústia diante da própria morte e sua eventual assunção numa forma de vida decidida, como também o problema fundamental da metafísica passa a ultrapassar do âmbito da filosofia e impregna a ordem da cultura como um todo.

Tal impregnação da linguagem cotidiana se mostra como uma modalidade específica de perceber e compreender o mundo, a natureza e as pessoas. Segundo Heidegger, essa modalidade se define por uma gramática de extração e acúmulo, onde os objetos (Gegensand) passam a valer por sua consistência, duração e certeza (Bestand). O Reno, que permitia outrora que o camponês transpor- 
tasse suas frutas e verduras, dependendo do tempo, passa a ser pensado como energia potencial para uma usina hidroelétrica, e sua beleza como potencial de exploração econômica pela indústria do turismo. Uma nova linguagem havia se apropriado da relação entre os sujeitos e o mundo: a linguagem instrumental adquirira uma amplitude simultaneamente planetária e cotidiana, presente na vida de todos e de cada um. Nesse sentido, o termo que melhor expressa essa nova gramática de extração e acúmulo, gramática na qual a existência humana passa a ser dita, seria aquela da técnica. Com efeito, todos os entes, toda experiência valem nessa gramática apenas como instrumento, ferramenta. Contudo, na medida em que essa gramática técnica envolve o mundo inteiro como uma rede, a nada permitindo que lhe escape, nem mesmo aquele que crê criar os novos instrumentos dessa rede, uma diferença fundamental deve ser marcada com o sentido cotidiano de técnica. Em seu sentido comum, uma técnica é sempre uma opção livre daquele que a emprega. Ora, se nem mesmo a forma como o homem compreende seu mundo escapa a essa gramática de extração e acúmulo, então ele não tem mais a liberdade, a possibilidade de interromper a técnica em sua expressão planetária. Nesse sentido, a técnica não pode mais ser compreendida como um instrumento neutro, à mão do homem. Em seu texto A questão da técnica, Heidegger busca então um novo termo, capaz de pensar o que subjaz a tal gramática globalizada da extração e do acúmulo planetária, gramática que se infiltrara na própria alma da cultura, propondo o termo Gestell. Entre os diferentes sentidos dessa palavra em alemão, presentes na construção de Heidegger desse conceito, um se destaca: a Instalação, termo que evoca a rigidez, o anonimato e a inquietante mecanicidade do que está sendo descrito.

No tema que nos interessa, a saber a mudança do lugar social da ciência, o efeito da Instalação é bastante claro. Essa se transforma, sob a égide da Instalação, no monopólio da operacionalidade técnica em torno da certeza da representação. É evidente que esse monopólio exclui, invariavelmente, qualquer outra forma de questionamento do real, mesmo aquela da "curiosidade neutra" que até então caracterizou o fazer científico. A certeza da representação, ou seja, a formalização da linguagem necessária ao saber científico (Silva Jr., 2007), passa, desse modo, a funcionar exclusivamente segundo fins operacionais. Perdem-se assim categorias essenciais daquilo que marca a diferença entre o saber da ciência e o saber técnico, ou seja, o desconhecimento e o desejo de saber como causa da investigação (Granger, 1994). Claro está que, para Heidegger, a mobilização total descrita por Jünger seria apenas a ponta de um gigantesco iceberg que se desdobraria na própria forma de compreensão do humano e da natureza.

Esse novo diagnóstico heideggeriano é o que nos interessa aqui, pois inclui uma alteração na própria forma de expressão, de experiência e de compreensão do que é o sofrimento. No âmbito social, essa alteração ocorreria, entre outras formas, com o surgimento de uma nova diagnóstica, isto é, uma forma de compreensão e nomeação dos sofrimentos apoiada na linguagem científica que 
se refletem na singularidade do sujeito, com o surgimento de novos modos de subjetivação, fundamentalmente impermeáveis aos anteriores.

\section{A superação técnica da ciência psiquiátrica}

De fato, talvez um dos exemplos mais claros de como a ciência passa a ser definida pela técnica seja aquele da recente história da Psiquiatria. Enquanto testemunha do surgimento de um novo modo de compreensão e de nomeação do sofrimento, essa história teve um papel fundamental em dois sentidos. Em primeiro lugar, pelo seu inédito sucesso enquanto uma ciência prática, com o desenvolvimento - a partir dos anos 1950 - de uma tecnologia de medicamentos finalmente eficaz no controle dos efeitos da angústica, com o meprobamato (1950), das depressões com a imipramina (1957) e dos sintomas da esquizofrenia, com a clorpromazina (1952), assim como com o desenvolvimento do rimeiro establilizador de humor com o litio (1954) (Barreto; Iannini, 2017). Era a primeira conquista capaz de legitimar efetivamente a Psiquiatria no campo da medicina, após praticamente 200 anos de desconfortável comparação com as outras especialidades médicas, dada sua limitação à mera descrição e taxonomia das doenças. Em segundo lugar, a partir da surpreendente reorientação epistemológica, reorientação com efeitos radicais na produção de conhecimento da teoria psiquiátrica. Com efeito, a história dos manuais das séries DSM e CIDI demonstra um progressivo abandono do ponto de vista causal e a definitiva adoção de critérios pragmáticos e convencionalistas de diagnóstico e tratamento das doenças mentais em sua versão dos anos 1970. Tal reorientação epistemológica, que exige da Psiquiatria seu distanciamento de uma nosologia crítica e reflexiva em nome de uma nosografia purificada de quaisquer hipóteses, busca oferecer critérios exclusivamente empíricos para o diagnóstico das doenças, apontando não apenas quais sintomas, como também a quantidade e duração necessárias para a atribuição de um certo diagnóstico. Uma reorientação convencionalista da divisão entre o normal e o patológico completa as condições de base que permitirão à Psiquiatria um salto para além das fronteiras da medicina, a saber, para aquele da industria do bem-estar, numa bem-sucedida joint venture acadêmico-empresarial.

Cabe antes refletir um pouco mais sobre como esses dois avanços da Psiquiatria podem ser interpretados como fenômenos típicos da era da Instalação. De fato, ilustrando com perfeição a inversão entre ciência e técnica indicada por Heidegger, a "história natural da doença", isto é, o pressuposto de uma coerência interna deixou de ser resultado da observação clínica e da dedução hipotética dos processos autônomos do sujeito e passou a ser definida pelos efeitos de novas drogas sobre o comportamento. Nesse sentido a Psiquiatria inverteu a ordem entre o processo de produção de conhecimento e aquele de ação terapêutica vigente até então: ao invés de esperar passivamente as doenças surgirem, serem descritas, isoladas e serem submetidas a sucessivas tentativas terapêuticas, ela passa a definir de antemão e criar ativamente as patologias de sua competên- 
cia, organizando-as em torno dos agrupamentos de sintomas que desaparecem sob a ação de drogas com ação neuroquímica.

Essas mudanças epistemológicas da Psiquiatria foram preliminares a um segundo processo de renomeação dos sofrimentos hegemônico na era da Instalação, o mercantil. De fato, se, por um lado, a Psiquiatria adquiriu um maior poder terapêutico apoiada nos avanços da neurofisiologia e neuroquímica; por outro, o princípio convencionalista da classificação das doenças foi um passo estratégico para o desencadeamento e manutenção de um processo virtualmente infinito de renomeação de grupos de sintomas, numa inquietante importação de uma das estratégias mais eficazes do marketing, aquela da obsoletização programada, tendo conseguido criar o perfeito consumidor para a indústria farmacêutica. Ora, cabe aqui um breve desvio para que se possa compreender como aquilo que veio a se tornar o principal motor da economia do século $\mathrm{XX}$, o marketing e suas estratégias de produção do consumo (Silva Jr.; Lirio, 2005) contribuiu para a criação de uma nova diagnóstica psiquiátrica no século XX.

\section{O sofrimento nos tempos do marketing}

A Psicanálise não está isenta da história do marketing, pelo contrário, participa ativamente dessa praticamente desde seu nascimento. Em 1909 Freud e seus discípulos haviam deixado uma forte impressão sobre o meio médico dos Estados Unidos com a apresentação de uma teoria racional sobre os processos irracionais da alma (Hale, 1971, 1995 apud Illouz, 2006, Fontenelle, 2017). Além disso, a teoria freudiana demonstrava a presença desses processos no cotidiano, o que implicava redefinir as fronteiras entre normalidade e patologia em sua base, a saber modificando o próprio modelo do que é um sujeito. A tomada em consideração das emoções como realidades em si, fora das categorias do pensamento moralizante, não era mais algo impensável. A literatura e as revistas femininas passaram a popularizar esse novo saber científico sobre o espírito apresentado pela medicina e um discurso sobre a interioridade começou a tomar a cena pública desse país (Illouz, 2006).

Uma figura-chave na instituição prática e constituição teórica do marketing foi Edward Bernays, sobrinho de Freud, e que, supostamente, se apoiando na teoria psicanalítica, lançou as bases da manipulação simbólica como instrumento do consumo das massas (Castro, 2013). Bernays (1947) define sua ciência como uma "engenharia do consentimento", isto é como "arte de manipular as pessoas", e defendia que essa era uma forma de proteção da democracia, uma vez que as massas eram "fundamentalmente irracionais" e em cuja opinião "não se poderia confiar". Não é uma surpresa sua participação ativa por várias décadas no Comitee for Public Information, órgão estatal do governo norte-americano dirigido a manipular a opinião política das massas a partir da tecnologia desenvolvida no marketing.

Assim, no meio dos anos 1920 pode nascer nos Estados Unidos um novo campo de estudos, chamado de "economia de consumo". Esse desenvolveu no- 
vas técnicas no campo da economia, como o crédito pessoal, mas, principalmente, a publicidade, que deveria descobrir e explorar o poder da carga simbólica dos produtos. Charles Kettering, engenheiro da General Motors e inventor de mais de três centenas de patentes em vários domínios, foi um dos primeiros a capturar o núcleo do que iria então se tornar a máxima da ciência do consumo: "A chave da prosperidade econômica, dizia ele, é a criação de uma insatisfação organizada" (apud Rifkin, 2006, p.42 ). Chegando a conclusões similares, um longo relatório encomendado pelo presidente Hoover ao Comitê sobre as $\mathrm{Mu}$ danças Econômicas Recentes foi publicado em 1928. A conclusão desse relatório suscita uma inquietante familiaridade com a teoria do desejo psicanalítica:

A investigação demonstra de maneira segura aquilo que havíamos tido por muito tempo como verdade em teoria, a saber, que os desejos são insaciáveis; que um desejo satisfeito abre caminho para um outro. Para concluir, diremos que no plano econômico um campo sem limite se abre a nós; novas necessidades abrirão sem cessar o caminho para outros ainda mais novos, desde que os primeiros sejam satisfeitos. [...] A publicidade e outros meios promocionais $[. .$.$] atrelaram a produção a uma potência motriz quantificá-$ vel. [...] Nossa situação é promissora, nosso ímpeto extraordinário. (apud Rifkin, 2006, p.46-47)

Não se trata apenas de vender imagens e discursos através do cinema, televisão, rádio, internet - veículos de venda de mercadorias de natureza cultural -, mas também da utilização da própria imagem como um sutil instrumento da venda de mercadorias. Não apenas ideais estéticos e sensoriais podem se tornar meio da indústria da produção de consumo de roupas, hábitos de higiene ou alimentares. Pode-se também produzir identidades, prazeres, valores morais, e mesmo formas de adoração religiosa, ou seja, qualquer processo psíquico pode tornar-se uma ferramenta eficaz da produção de consumo. Mais especificamente, tal como diagnosticado por Adorno e Horkheimer, a cultura adquiriu a função de meio de produção de comportamentos de consumo. Para tanto, deve-se simplesmente, a cada vez, seja criar, seja renomear experiências em comportamentos humanos comercializáveis (Silva Jr.; Lirio, 2005). De fato, pode-se dizer que o que caracteriza a versão econômica da Instalação diz respeito, sobretudo, ao aspecto exponencial desse processo de tradução de formas de sociabilidade e de cuidados de si em elementos que as tornem acessíveis à lógica mercantil.

Ora, apesar de seu ineditismo na história das doenças, não será uma surpresa que nossas formas de adoecimento sejam incorporadas em tal lógica de renomeação mercantil, numa duvidosa articulação do campo da cultura com o campo da indústria farmacêutica das drogas psicoativas. Para tanto, o sofrimento psíquico cotidiano exige uma série de modificações da linguagem, dos sujeitos, das instituições de saber e da cultura (Parry, 2003; Bolguese, 2004; Silva Jr., 2016).

Esse segundo processo inclui elementos que vão além da competência psiquiátrica. Em primeiro lugar, aquilo que Bolguese (2004) apresenta, em seu 
trabalho, como a "banalização" e a "naturalização" da depressão. A banalização é constatável na crescente popularização dos discursos sobre a depressão no âmbito leigo, assim como uma inflação inusitada do diagnóstico de depressão no âmbito médico como um todo. Com efeito, para além da clínica psiquiátrica enquanto tal, o diagnóstico e o tratamento a depressão são hoje comumente realizados por clínicos gerais, ginecologistas e outros especialistas sem formação psicopatológica específica. Nesse sentido, não apenas a depressão se banalizou, como o sofrimento psíquico como tal. Mas tal banalização está associada a discursos que a naturalizam, isto é, que a apresentam como uma condição "natural" do ser humano, resultante de distúrbios orgânicos, e, portanto, em última instância, desvinculados do contexto histórico em comum, bem como da historicidade de cada um.

Através do marketing, uma verdadeira Weltanschaunng organicista foi construída para sustentar a identidade do consumidor das drogas psicoativas. Com efeito, o sentido freudiano desse termo vale com perfeição para a promoção dessa narrativa, uma vez que ela visa dar um sentido geral à existência e assim garantir o sujeito contra seu desamparo incontornável. Essa Weltanschauung, em sua ressignificação do sofrimento enquanto disfunção puramente orgânica, priva contudo o sujeito do sentido do sofrimento como forma de reação aos acontecimentos, e, portanto, invalida, a priori, privando-o assim de sua potencialidade crítica na esfera da vida social.

Com efeito, na lógica do discurso que naturaliza o sofrimento, o responsável último pela doença se torna o corpo inerte, ao soma, que apresentaria um déficit ou irregularidade deste ou daquele elemento ou processo neurofisiológico. Sua insatisfação, seu inconformismo e sua tristeza deixaram de ser reações compreensíveis às adversidades de sua existência e passaram a significar distúrbios neuroquímicos, passíveis de uma correção medicamentosa. Entretanto, esse mesmo discurso o informa que a ciência já se encontra suficientemente avançada para oferecer uma solução concreta para tais problemas, através de medicamentos capazes de corrigir tais deficiências. Nesse momento o sujeito está preparado para começar a exercer não apenas através de seus desejos e sonhos, como também através do seu sofrimento, seu papel "cívico" no admirável mundo novo do capitalismo, aquele de consumidor. E contudo, o trabalho de recodificação não termina aqui, já que um novo problema se coloca, aquele de conquistar a fidelidade desse novo consumidor. Será então que outras competências do marketing serão convocadas a atuar. Assim, entre outros elementos que constituem um quadro semântico de extrema coerência, o marketing medicamentoso não hesita em apresentar a alegria como um estado afetivo à mão, passível de ser obtido pela medicação a qualquer momento e por toda a vida.

Vimos como a renomeação acadêmico-empresarial do sofrimento, voltada para a produção e controle do comportamento de consumo e apoiada sobre uma ampla gama de processos científicos e do marketing, produz e oferece uma 
Weltanschauung no sentido freudiano do termo. Vejamos agora como o sujeito faz para ocupar seu lugar nesse discurso, assim como os efeitos retroativos dessa ocupação sobre ele. Em outras palavras, se há uma "poética" da racionalidade diagnóstica, ou seja, se há uma produção discursiva desta, há também uma "estética", uma forma de recep̧cão desta última pelos sujeitos que a incorporam e que propagam seus efeitos ontológicos. Esse lugar pode ser pensado como estruturas da linguagem que Foucault nomeou como modos de subjetivação.

\section{Novos sofrimentos, novos sujeitos}

Um inquietante fenômeno pode ser observado hoje, pois ele articula essa nova racionalidade diagnóstica, promovida pelo programa DSM, a novas formas de subjetivação no sentido foucaultiano dessa expressão. É atualmente comum que as pessoas evoquem um diagnóstico psiquiátrico ou psicanalítico como uma forma de autoapresentação: declaram ser neuróticos obsessivos (TOC), histéricas, borderlines, deprimidos, como quem descreve a profissão ou a origem da família. A autonomeação a partir de um quadro psiquiátrico descreve ainda uma disfunção, mas nada que aponte para uma responsabilidade do sujeito.

Ora, tais efeitos discursivos, isto é, o estabelecimento de identidades a partir de discursos fundados sobre saberes, constituem um dos focos dos trabalhos de Michel Foucault, particularmente naquilo que ele nomeou como "modos de subjetivação". Esse conceito é portanto adequado para situarmos a forma de apropriação dos sujeitos da Weltanchauung organicista do sofrimento na era da Instalação. Ele nos permitirá localizar com relativa precisão o modo de exclusão do sujeito do inconsciente por esta Weltanschaumng enquanto uma supressão de sua potencialidade enunciativa.

Sob a expressão "modos de subjetivação", Foucault define basicamente duas coisas. Em primeiro lugar, que os modos de subjetivação são paradoxalmente equivalentes a modos de objetivação do sujeito, particularmente na relação dos sujeitos com o saber e o poder (Foucault, 1994, p.223). Os sujeitos se constituem ao se assumirem como objeto de um saber ou poder. O conceito de modos de subjetivação diz respeito a um fenômeno discursivo de natureza social. Está presente nas narrativas e nos discursos enquanto condensações da língua e da cultura, enquanto preferências gramaticais, padrões estéticos e morais diferentes de uma região a outra, de um tempo a outro no interior de uma mesma língua. A natureza dos modos de subjetivação é discursiva e serve à diferenciação, pertença e exclusão, enfim, à legitimação de um sujeito e seus atos no interior de um código social. Dizem respeito ao que é considerado um bem ou um mal para o sujeito, assinalando sua posição moral. São assim fenômenos discursivos que legitimam saberes, partilham identidades e orientam moralmente.

De que modo o sujeito que interessa à Psicanálise, a saber, o sujeito do inconsciente, se articula e reage aos modos de subjetivação? De fato, esses processos de ocupação dos discursos e laços sociais pelo sujeito são também pensáveis como soluções do sujeito a seus impossíveis, enfim, como modalidades de 
tratamento do real, do excesso pulsional, enfim, do que não tem sentido. Ora, a cisão constitutiva do sujeito pensada pela psicanálise tem como correlato uma forma precisa de oposição, aquela entre o enunciado e a enunciação. O sujeito psicanalítico, aquele que interessa como porta-voz da verdade, é o sujeito da enunciação. A partir de tal posicionamento, Lacan coloca em questão o pressuposto de uma metalinguagem tanto em sua incidência clínica quanto teórica. Isso significa que a afirmação "não há discurso sobre os discursos, ou não há Outro do Outro" é uma posição que implica a renúncia ao amparo ontológico oferecido pelo pressuposto de uma metalinguagem. Podemos, analogamente ao que Freud via na ciência, considerar essa posição como aquela da Weltanschauung da psicanálise lacaniana.

Como alternativa a tal renúncia ao enunciado como garantia ontológica Lacan promove o resgate da enunciação como abertura privilegiada à verdade. Naturalmente, não se trata do mesmo tipo de verdade que a metalinguagem garantiria a todos os discursos, nem tampouco da verdade como adequação, presente na epistemologia freudiana, mas de uma verdade marcada pela fugacidade, uma verdade atrelada à noção de acontecimento irreversível, uma verdade pensada enquanto desvelamento daquilo que não quer se revelar.

Se a experiência da clínica psicanalítica põe em causa o caráter insubstituível da enunciação, na metafísica, por sua vez, temos uma primazia do enunciado. Ora, os modos de subjetivação definidos por Foucault são, nesse sentido, compreensíveis como formas de subjetivação "metafísicas", uma vez que nelas o sujeito se nomeia como o objeto de um saber anterior, um saber que deve garantir a verdade sobre as verdades. Não é portanto um acaso que os modos de subjetivação da contemporaneidade tendam a suprimir o valor da enunciação, na medida em que negam a autonomia de sua eficácia. É o caso também das autoapresentações onde o sujeito se filia a uma categoria diagnóstica como quem pede abrigo para a própria verdade. De fato, tais modos de subjetivação afetam a relação do sujeito com o discurso, numa inegável direção de obsoletização da enunciação como forma de habitar a linguagem, uma vez que só importa o já dito e garantido por uma autoridade. Os modos de subjetivação contemporâneos evocam, nesse sentido, a metalinguagem científica, o discurso da ciência como garantia subjacente a todas as linguagens. Nesse contexto, a indiferença ao saber inconsciente e ao seu deciframento parece, com efeito, ser uma das tendências do modo de subjetivação contemporâneo (Askofaré, 2013, p.85).

Mas essa derivação identitária do sofrimento não é a única que se apresenta como um desafio para a Psicanálise. Na medida em que essas subjetividades contemporâneas são inseparáveis de uma certa economia de mercado que organiza instituições de ensino, hospitais, jurisprudências específicas, assim como sistemas pré-formatados e lucrativas dos cuidados de si, um posicionamento da Psicanálise diante da cultura é necessariamente convocado. Retomando o caminho percorrido, os novos jogos de verdade sustentam os modos de subjeti- 
vação atuais, pautados por uma compreensão organicista e convencionalista das patologias, e mantidos em movimento por recursos de persuasão importados do marketing afetam a potência enunciativa dos sujeitos. Estamos portanto diante de uma realidade social que afeta a economia psíquica dos sujeitos, suas estruturas de gozo e sofrimento segundo uma modalidade específica. Esse parece ser o efeito mais visível da era da Instalação sobre o psiquismo e sua expressão do sofrimento, a saber, o progressivo silenciamento do sujeito da enunciação pelo sujeito do enunciado. De certo modo, isso já estava implícito na própria "virada" heideggeriana, a qual denunciava uma obsoletização do sujeito e de suas “decisões autênticas” pela gramática de uma outra modalidade de alienação introduzida pela Instalação.

$\mathrm{Na}$ Instalação, a linguagem e as relações sociais se realizam em uma gramática que modifica as formas de compreensão e de narração do sofrimento, organizados em lógicas acadêmico-empresariais com novos efeitos sobre o sujeito. Nesses novos discursos sobre o sofrimento, o sujeito saudável é aquele soberano de si, senhor de suas vontades, seu destino e com dever de satisfazer seus desejos. Aquele que sofre, contudo, não é de modo algum responsável ou partícipe de seu sofrimento, ele é antes uma vítima inocente de uma disfunção orgânica, facilmente corrigível por novos medicamentos. Tal modo de subjetivação, marcado pela hegemonia da narrativa organicista do sofrimento, promove uma indiferença, ou mesmo um sufocamento do sujeito do inconsciente. Note-se que este sufocamento dificilmente pode ser questionado pela teoria freudiana, na medida em que ele se lhe escapa como problemático. O sufocamento do sujeito do inconsciente, o desinvestimento social da enunciação como a forma de existência por excelência do sujeito não são (ainda) hegemônicos, e as reações inconscientes do psiquismo a esse sufocamento se organizam em novas economias do gozo (Silva Jr., 2008, 2012a, 2012b, 2014). Compreender os limites conceituais da leitura freudiana da cultura e preparar uma leitura das formas de resistência do inconsciente à era da Instalação é a proposta da parte final deste texto.

\section{Limites da elipse}

Como vimos, o modelo de Freud para as patologias do social se funda sobre uma concepção bicêntrica, simultaneamente naturalística e narrativa, dois centros de uma elipse que podem ser tomados como princípios de sua reflexão. Freud parte da ideia de uma continuidade entre a natureza e o discurso, e da ideia que o discurso científico deve ser considerado como aquele que não cede sobre a verdade, isto é, não se sujeita às ilusões confortáveis, como o faz o discurso religioso. Ora, justamente tais princípios coincidem com precisão com os jogos de verdade que sustentam a nova discursividade do sofrimento humano: a natureza radicalmente orgânica da experiência psíquica do sofrimento, e a ascensão da racionalidade científica ao estatuto de avalista da verdade. Essa "coincidência" ao tornar impossível um distanciamento crítico - pois não pode haver questionamento daquilo que funciona como um fundamento da verdade - é, a 
meu ver, responsável pelo "ponto cego" de Freud frente aos fenômenos psíquicos e os sofrimentos sociais da era da Instalação.

Pouco há o que dizer sobre a primeira coincidência, a saber, aquela do postulado de uma continuidade entre a natureza e o discurso com a ideologia de uma essência orgânica do sofrimento psíquico. Ela está presente na ideia de uma fonte biológica da pulsão, e sustenta a própria adesão da Psicanálise a uma Weltanschauung científica (Freud, 1982d, p.587). Em outra ocasião, Freud (1982e, p.583) chega a afirmar que o avanço nas descobertas hormonais e neurofisiológicas poderia, em seu futuro, a tornar a Psicanálise obsoleta, demonstrando a radicalidade com a qual ele aderia a esse primeiro postulado. Como contraponto a essa adesão, cabe também notar que essa coincidência nunca invalidou, pelo contrário, sempre conviveu muito bem com o segundo centro da elipse freudiana, o centro discursivo enquanto lugar de trabalho com a verdade. Aos olhos de Freud, a verdade pode ser velada ou desvelada justamente pelo fato de a cultura estar sempre em constante conflito com sua origem pulsional. Ou seja, modelo da elipse é mais "forte" que cada um de seus centros.

Ora, o "ponto-cego" mais importante da "coincidência" resulta evidentemente daquela entre o segundo postulado freudiano, isto é, da imunidade que a racionalidade científica gozaria frente às forças inconscientes, e a crescente ideologia cientifica como garantia da verdade. Sendo aquele discurso que não cederia sobre a verdade, a Weltanschaunng científica valeria também como uma medida confiável das inevitáveis ilusões e fantasias regressivas.

A favor desse argumento, vejamos como Freud considerava a ideia de uma sociedade radicalmente organizada por princípios racionais. A interessante discussão que ele trava em Sobre uma visão de mundo - Zur einer Weltanschauung (Freud, 1982d) com a revolução marxista pode indiretamente refletir a posição de Freud diante da orientação pela razão em matéria de governo. Ao criticar "os bolcheviques", seguidores da teoria de Marx, a objeção de Freud se limita a um só ponto: ele olha com circunspecção sua energia revolucionária, que se aproxima inquietantemente dos excessos da fé religiosa e seus perigos reformatórios. Trata-se de um movimento revolucionário, segundo Freud, oriundo de uma teoria científica que derivou, contudo, em uma Weltanchaunng indistinguível daquela presente nos tempos da inquisição. Por outro, em relação à própria teoria científica na origem desse movimento, ele lembra que uma forma específica de determinação da consciência não parece ter sido levada em conta por Marx, justamente aquela trazida à luz pela Psicanálise, a saber, a determinação do passado, que atua através dos processos psíquicos inconscientes através de nossos ideais e da tradição cultural, fundamentalmente transmitidos pelo Supereu.

Tal determinação do passado faz três exigências irracionais ao presente, cuja satisfação é propiciada pelas Weltanschaunngen. Em primeiro lugar, a necessidade de um sentido subjacente à incoerência e arbitrariedade dos acontecimentos do destino, donde a força das narrativas religiosas. Em segundo lugar, 
a necessidade de uma direção para nossas ações morais e, finalmente, a necessidade de proteção diante de nosso desamparo estrutural. Dessas duas últimas necessidades, poderíamos compreender a origem intrapsíquica da sedução exercida pelos líderes sobre as massas, assim como aquela da associação Deus/Pai. Deduz-se disso que, para Freud, essas são exigências impossíveis de serem satisfeitas no âmbito da racionalidade científica. Para Freud, a racionalidade é desde sempre delimitada, finita em seu poder. Essa característica a imunizaria contra o risco de um funcionamento regredido no psiquismo, ou seja, uma forma de finitude constitutiva que seria simultaneamente o que garantiria à Weltanschaunng científica sua indiferença frente às ilusões e às demandas inconscientes. A crítica que a Psicanálise teria à teoria marxista seria a de essa aparentemente ter esquecido do caráter fragmentário e incompleto da ciência, em nome de uma revolução pela justiça social, ou seja, à redução da causalidade do sofrimento aos fatores atuais e presentes. O reparo não seria difícil de ser feito: “aquele que conseguir", escreve Freud (1982d, p.606), “demonstrar em casos singulares, de que modo esses diferentes momentos - a disposição pulsional humana, suas variações de raça, suas modificações culturais sob as condições da organização social, do trabalho e dos seus possíveis dividendos - se configuram, impedem e fomentam uns aos outros, aquele que consegui-lo terá conseguido levar as consequências do marxismo a uma verdadeira teoria da sociedade. Pois também a sociologia, que trata das relações dos homens na sociedade, não pode ser mais do que psicologia aplicada. Rigorosamente, só há duas ciências: a psicologia, pura ou aplicada, e a teoria da natureza”.

Mas, como vimos, para além desse funcionamento propriamente imaginário da racionalidade sociológica de origem marxista, apontado e "corrigido" aqui por Freud, era notório que algo havia mudado na própria estrutura das instituições e na linguagem cotidiana. Uma mudança que já era perceptível no cotidiano da cultura, para além dos movimentos revolucionários ou dos esforços de guerra, a saber, a gramática da ciência, que passara de uma "busca desinteressada pela verdade" para uma "operacionalidade sobre o real". Teria Freud percebido tais mudanças da cultura? De fato, alguns elementos dessa mudança, como o desencantamento do mundo e a reificação do psiquismo, foram percebidos por Freud, mas foram por ele considerados como processos restritos a uma cultura, a norte-americana. Para Freud, tais “americanismos”, ou seja, e que não corriam o risco de atravessar o Atlântico. Em uma carta a Marie Bonaparte, Freud resume essa cultura a uma forma pragmatismo radical citando uma publicidade que considera "como a mais ousada e eficaz publicidade norte-americana": "Why live, if you can die for ten dollars?" (Freud, 1960).

$\mathrm{O}$ que a Weltanschauung científica de Freud não chega assim a considerar é a possibilidade da própria racionalidade científica pudesse se transformar em um discurso radicalmente operacional, e, contudo, simultaneamente moral. Diferentemente do destino idealizado que a teoria "originalmente científica" 
de Marx sofreu segundo Freud, a nova face operacional da ciência funciona sem ideais nem utopias. Nesse sentido, seu funcionamento não é análogo ao de uma Weltanschaunng religiosa e tampouco com aquele de grandes figuras de liderança e supostos donos da verdade. Ainda que precisamente essa seja uma das derivações da racionalidade científica sob a batuta do marketing, a saber, a "verdade orgânica" do sofrimento e de sua cura, há aqui uma diferença: trata-se, a cada vez, de soluções meramente instrumentais, sem promessas de redenção final. Ainda assim, essa instrumentalidade contém uma moral, na medida em que ela passa a pautar categorialmente a totalidade dos valores possíveis, dos leques de escolhas, enfim do que é possível desejar. Nessa sintaxe de crença compulsória na contabilidade total do mundo da Instalação há uma inquietante compatibilidade com a Weltanschaunng científica freudiana, sempre fragmentária e transitória, visão animada pelo poder desalienante que a verdade teria como tal. Com efeito, esse inquietante funcionamento que o discurso científico assume na organização social não pode ser capturado pela crítica freudiana, apoiada em uma versão do discurso científico que estaria imune ao seu funcionamento no psiquismo na chave de depósito da totalidade da verdade. Tudo se passa como se a racionalização, figura tão familiar a Freud no âmbito da clínica psicanalítica, tivesse se transformado em uma nova moral cultural precisamente pelo seu caráter totalizante, isto é, na medida em que é tomada como a única forma de saber.

\section{Verdade como adequação, como desvelamento e como cálculo}

No diagnóstico heideggeriano de nosso tempo, a Instalação representa, para além de uma mudança na gramática da relação do homem com o mundo, uma alteração no sentido da verdade. Comparada à verdade como desvelamento, que constiuía o cerne hermenêutico de Ser e tempo, a verdade no tempo da Instalação não se refere mais ao jogo de esconde-esconde com a finitude, tal como a queda funciona para o Dasein angustiado diante de sua possibilidade de não-mais-estar-aí. Tampouco a Instalação vela o desamparo pela idealização, como o faz, segundo Freud, o discurso religioso ou ideológico. Nesse sentido, ela não poderia ser criticada como uma relação deficitária com a verdade dos desejos dos sujeitos, como é o caso das patologias do social compreendidas pela perspectiva da filosofia da história freudiana. A Instalação simplesmente transforma a finitude e o desamparo num "custo" a ser comparado com um "beneficio". Tal recodificação do sofrimento em um cálculo entre possibilidades mutuamente excludentes dificilmente pode ser qualificado como uma regressão a um pensamento infantil. Com efeito, esse cálculo não exclui a finitude e o desamparo do sujeito que escolhe, ele os contabiliza segundo finalidades operacionais. Assim, o sentido da verdade na Instalação segundo a chave do cálculo e da eficácia administrativa. Em qual sentido essa chave pode ser criticada?

Podemos, por exemplo, pensar que o caráter simultaneamente totalizante e totalitário, o monopólio dessa forma de pensar o sofrimento, que sempre tem soluções técnicas para qualquer problema, desde que se tenham recursos 
financeiros para comprá-las, exclui a questão sobre seus próprios fundamentos, tal como o velamento metafísico da verdade. Não há lugar, por exemplo, para nos questionarmos se todas as experiências de sofrimento seriam de fato indesejáveis e, portanto, contabilizáveis. A dor de um luto, por exemplo, possui um valor em si e suprimí-la com antidepressivos significaria um empobrecimento de nossa vida.

\section{Referências}

ASKOFARÉ. S. D'un discours l'Autre. La science à l'épreuve de la psychanalyse. Toulouse: Presses Universitaires du Mirail, 2013.

BARRETO, F. P.; IANNINI, G. Introdução à psicopatologia lacaniana. In: TEIXEIRA, A.; CALDAS, H. Psicopatologia lacaniana. Belo Horizonte: Autêntica, 2017.

BERNAYS, E. The Engineering of Consent. Annals of the American Academy of Political and Social Science. March 1947.

BOLGUESE, M. S. Depressão \& doença nervosa moderna. São Paulo: s. n., 2004.

CASTRO, J. C. L. Edward Bernays and Freudian group psychology. In: Proceedings of the International History of Public Relations Conference. Bournemouth (UK): Institute for Media and Communication Research, 2013. p.188-93.

DERRIDA, J. Etats d'âme de la psychanalyse - Adresse aux Etats Généraux de la Psychanalyse. Paris: Galilée, 2000.

FONTENELlE, I. A. A cultura do consumo. São Paulo: Fundação Getúlio Vargas. 2017.

FREUD, S. Sigmund Freud an Marie Bonaparte, 13. August 1937. In: FREUD, E. L. (Ed.) Briefe 1873-1939. Frankfurt a.M.: S. Fischer, 1960. p.429.

. Drei Abhandlungen zur Sexualtheorie. Studienausgabe. Frankfurt-am-Main: Fisher Taschenbuch Verlag [1905], 1982a. v.5.

. Die «kulturelle» Sexualmoral und die moderne Nervosität. Studienausgabe. Frankfurt-am-Main: Fisher Taschenbuch Verlag [1908], 1982b. v.9.

. Warum Krieg? Studienausgabe. Frankfurt-am-Main: Fischer Taschenbuch Verlag [1937a],1982c. v.9.

. Neue Folge der Vorlesungen zur Erführung in die Psychanalyse. 35 Zur einer Weltanschaumng. Frankfurt-am-Main: Fischer Taschenbuch Verlag [1933], 1982d. v.I.

Neue Folge der Vorlesungen zur Einführung in die Psychoanalyse. 34, Aufklärungen, Anwendengen, Orientierungen. Studienausgabe, Frankfurt-am-Main: Fischer Taschenbuch Verlag [1933], 1982e. v.I.

Sigmund Freud Briefe an Wilhelm Fliess 1887-1904. Frankfurt am Main: Fischer Verlag, 1986.

Das Unbehagen in der Kultur. Gesammelte Werke. Band XIV. Frankfurt am Main: Fischer Taschenbuch Verlag [1930], 1999. 
FREUD, S. Die endliche und die unendliche Analyse. Studienausgabe. Frankfurt-am-Main: Fischer Taschenbuch Verlag [1937b], s. d., v.XI, p.364.

GRANGER, G. G. A Ciência e as ciências. São Paulo: Editora Unesp, 1994.

HALE, N. Frend and the americans. The beginings of Psycho-Analysis in the United States. New York: Oxford University Press, 1971

. The rise and crisis of Psycho-Analysis in the United States: Freud ant the Americans 1917-1985. New York: Oxford University Press, 1995.

HAMACHER, W. Premisses: Essays on philosophy and literature from Kant to Celan. Stanford: Stanford University Press. 1999.

HEIDEGGER, M. Sein und Zeit. Tübingen: Max Niemeyer Verlag, 1979.

Neske, 1990.

Die Frage nach der Technik. In: Vorträge und Aufsätze. Tübingen:

HINE, T. The total package: the evolution and secret meanings of boxes, bottles, cans, and tubes. Boston: Little Brown, 1995.

ILLOUZ, E. Les sentiments du capitalisme. Paris: Seuil, 2006

. La fabrique de l'âme standard. Le Monde Diplomatique, novembre 2011.

JÜNGER, E. Die Totale Mobilmachung. In: __. Werke. Stuttgart: Ernst Klett Verlag, 1960.

KETTERING, C. F. Keep the consumer dissatisfied. Nation's Business, 1929.

LACAN, J. La science et la verité. In:___ Écrits. Paris: Seuil, 1966.

FOUCAULT, M. L'Histoire de la Sexualité 2. L'usage des Plaisirs. Paris: Gallimard, 1984. Dits et écrits IV. Paris: Gallimard, 1994.

MILNITZKY, F. Uma psicopatologia do consumo: relação entre narcisismo e situações de consumo. In: __. (Org.) Desafios da clínica psicanalitica na atualidade. Goiânia: Dimensão Editora, 2006. v.1.

PARRY, V. The art of branding a condition. London: Medical Marketing \& Media, maio de 2003.

RIFKIN. La fin du travail. Paris: Éditions de la Découverte, 2006.

SILVA JUNIOR, N. Linguagens e pensamento. A lógica na razão e na desrazão. São Paulo: Casa do Psicólogo, 2007. (Col. Clínica Psicanalítica).

Corps et narration dans la modernité. In: GASPARD, J.-L.; DOUCET, C. Pratiques et usages du corps dans la modernité. Toulouse: Éditions Érès, 2008. p.65-84.

. L'irrémédiable souffrance de la culture. In: COELEN, M.; NIOCHE, C.; SANTOS, B. (Org.) Jouissance et souffrance. Paris: Éditions Campagne Première, 2012a. p.83-94.

Sublimation et vie économique. In: MIJOLLA-MELLOR, S. de. (Org.) Traité de la sublimation. Paris: Presses Universitaires de France, 2012b. p.438-57.

Souffrances dans la culture: une nouvelle architecture du masochisme. In : GASPARD, J.-L. (Org.) La souffrance de l'être Formes modernes et traitements. Toulouse: Éditions Érès, 2014. p.29-44. 
SILVA JUNIOR, N. Epistemologia psiquiátrica e marketing farmacêutico: novos modos de subjetivação. Stylus, Belo Horizonte, v.33, p.227-40, 2016.

SILVA JUNIOR, N.; LIRIO, D. R. The postmodern re-codification of perversion: on the production of consumer behavior and its libidinal grammar. International Forum of Psychoanalysis, v.14, p.217-23, 2005.

TAYLOR, C. Imaginários sociais modernos. Trad. Artur Mourão. Lisboa: Edições Texto e Grafia, 2010.

URBAN, B. (Org.) Freud und die Psychoanalyse. Reden, Briefe, Notizen, Betrachtungen. Frankfurt-am-Main: Fischer Taschenbuch Verlag, 1991.

RESUMO - O objetivo deste artigo é demonstrar que a chave conceitual do diagnóstico freudiano do Mal-estar na cultura é incapaz de apreender a alteração do lugar e do funcionamento social da ciência na cultura. A razão disso é considerada residir em sua concepção de ciência, supostamente a única forma de discurso capaz de garantir uma relação não ilusória e infantilizada com as fraquezas humanas. Tal concepção de ciência é incapaz de apreender sua assimilação pela técnica, tal como Heidegger formula em seu texto Sobre a técnica. Como exemplo dessa assimilação, realizo uma análise da alteração recente da epistemologia psiquiátrica e de sua assimilação pelas técnicas do marketing, assim como seus efeitos subjetivos desses novos modos de nomeação do sofrimento. Na conclusão, discuto a impotência crítica da concepção freudiana de ciência diante dessa assimilação e os diferentes sentidos de verdade em jogo.

PALAVRAS-CHAVE: Patologias do social, Metapsicologia, Instalação, Ciência, Técnica.

ABSTRACT - The aim of this article is to demonstrate that the conceptual key to the Freudian diagnosis of Civilization and its discontents is unable to grasp the changing place and social functioning of science in culture. The reason for this is deemed to reside in his conception of science, supposedly the only form of discourse capable of guaranteeing a relationship neither illusory nor infantile with human weaknesses. Such a conception of science is incapable of apprehending how it can be assimilated by technique, as Heidegger puts it in his text The question concerning technology. As an example of this assimilation, I analyze the recent change in psychiatric epistemology and its assimilation by marketing techniques, as well as the subjective effects of these new ways to name suffering. In the conclusion, I discuss the critical impotence of the Freudian conception of science in face of such assimilation and the different meanings of truth at play.

KErWORDS: Social pathologies, Metapsychology, Installation, Science, Technique.

Nelson da Silva Junior é professor livre-docente do Instituto de Psicologia da USP. Coordenador do Laboratório de Teoria Social, Filosofia e Psicanálise, juntamente com Christian Dunker e Vladimir Safatle. @- nelson1710@icloud.com

Recebido em 15.9.2017 e aceito em 7.10.2017.

I Instituto de Psicologia, Universidade de São Paulo, São Paulo, São Paulo, Brasil. 